\title{
Judicialização da saúde em Minas Gerais: saúde e democracia versus separação de poderes
}

Natália Baldessar Menezes

Mestre em Direito pela PUC-Rio

Procuradora do Município de Barbacena em provimento efetivo

Fundadora e Presidente da Associação de Procuradores do Município de Barbacena

Sumário: 1 - Introdução; 2 - Igualdade e democracia: valores base para as políticas de saúde; 3 - Separação de poderes: contornos constitucionais; 4 - Pesquisa jurisprudencial; 4.1 - Metodologia; 4.2 - Resultados; 5 - Considerações finais 6 Referências Bibliográficas

\section{RESUMO}

Este trabalho pretende analisar o fenômeno da judicialização da saúde quanto à determinação judicial de fornecimento de medicamentos. A fim de avaliar a validade da interferência do poder Judiciário nas políticas públicas de saúde, buscou-se interpretar os valores constitucionais da igualdade, democracia e separação de poderes. Para tanto amparamo-nos na doutrina de Bickel e de Post e Siegel. A pesquisa jurisprudencial oriundas de comarcas com desigualdades sociais mais acentuadas do estado de Minas Gerais assumiu importante papel neste estudo.

Palavras chave: Saúde - Separação de poderes - políticas públicas - igualdade democracia

\begin{abstract}
This works aims to analyse the drug dispensation trough Courts fenomenon. We intended to confront the judicial interference in public health policies with a systematic interpretation of the constitutional values of equality, democracy and separation of powers. For that we have taken the support of Bickel, Post and Siegel's studies. The jurisprudence research has selected decisions derived from the most unequal cities of the Minas Gerais state which were crucial key to this investigation.
\end{abstract}

Key words: Health - Separation of powers - public policies - equality - democracy

1 - Introdução

No cenário atual da judicialização da saúde, verificamos atualmente um acentuado grau de ingerência do Poder Judiciário no campo da saúde. Atrelado a um mal construído discurso de dignidade da pessoa humana e de garantia do direito à saúde, o Judiciário abre as portas para a concessão atomizada de medicamentos de altíssimo custo, e, não raro, para o tratamento de doenças crônicas.

Costuma-se pensar que a atuação do Judiciário nessa demandas se justifica por uma omissão do estado na prestação do dever constitucional de dar efetividade ao direito à saúde, entendendo que o Judiciário, na condição de vigilante dos direitos 
fundamentais, seria o elemento essencial para garantir a concretização das políticas públicas de saúde (SANTOS, 2010. p. 141).

A priori, nos é forçoso constatar que o nosso país, e o estado de Minas Gerais aqui utilizado como amostra - é marcado por uma profunda desigualdade social, de modo que nos cabe refletir se a concessão judicial de medicamentos de alto custo, frequentemente proveniente de grandes centros, onde os aparelhos públicos encontramse melhor equipados e há um maior acesso à justiça, é justificável, mormente quando o olhar para a realidade social descortina inúmeras regiões nas quais a população sequer tem acesso à água encanada e tratada, crianças padecem de desnutrição e mortalidade infantil chega a ser três vezes maior que a média brasileira.

Os recursos públicos, sabe-se, são limitados e, no campo da distribuição de bens sociais, prestam-se a garantir a todos - como um mandado de otimização - o acesso à educação, moradia, saúde. A moderna doutrina da judicialização de políticas públicas serve-se à concretização de bens sociais, genericamente; no entanto, o grande carro chefe é o direito à saúde, e nesse aspecto nos chama atenção as demandas para obtenção de medicamentos. Muito embora o direito à saúde não se resuma à assistência farmacêutica, é esta a demanda mais comum.

Questões sobre a dispensação de medicamentos frequentemente chegam aos Tribunais Superiores e o CNJ já editou duas recomendações ao Judiciário brasileiro sobre o tema: as recomendações números 31, de 2010, e 43, de 2013. Na mais recente delas, determinou-se a criação de varas especializadas de saúde pública, com o intuito de "garantir decisões mais adequadas e tecnicamente precisas" (CNJ, 2013).

A existência das recomendações indica ao mesmo tempo (e em igual medida) a gravidade da situação gerada pela frequente repetibilidade das demandas de saúde - e o consequente inchaço do Judiciário - e a incapacidade institucional deste poder para lidar com questões que fogem à sua capacidade técnica. Embora de grande valor, cabe frisar, as recomendações não vinculam a atividade judicial.

Desse modo, o presente trabalho busca verificar como se dá a atuação dos poderes no aspecto específico da dispensação de medicamentos com recursos públicos. Refletiremos sobre as premissas adotadas modelo estatal adotado, mormente quanto a separação e especialização de funções entre os entes federativos, a fim de avaliar se existe efetivamente falha no exercício de competência constitucional por algum dos poderes. Nesse caso, nos resta saber se a falha está no Executivo ou no Judiciário.

Para tanto, analisamos as premissas constitucionais de implementação das políticas públicas, avaliando a concretização dos valores de igualdade, justiça e democracia e realizamos uma pesquisa jurisprudencial de decisões sobre a dispensação de medicamentos com recursos públicos oriundas de comarcas de acentuando grau de desproteção social a fim de avaliar como o fenômeno tem se manifestado para as populações mais carentes.

A hipótese que se coloca é que a judicialização da saúde, não obstante as críticas, seria uma interferência válida se promover o incremento da saúde das populações mais carentes.

2 - Igualdade e democracia: valores base para as políticas de saúde

A prestação de políticas públicas, ante as limitações inerentes ao modelo estatal brasileiro não se prestam a atingir a todos os cidadãos indistintamente, não poderão, assim, a ser universais. As políticas públicas necessitam ter incidência desigual a fim de tornar os cidadãos de uma comunidade política mais iguais. Não seria politicamente justificável defender o contrário. Oferecer a quem já tem e recusar a quem não tem, não 
pode ser uma medida orientada a reduzir as desigualdades.

Rousseau já afirmava em seu Contrato Social que o fim do estado é garantir o bem estar de seus cidadãos e "a conservação e a prosperidade de seus membros" (ROUSSEAU, 2010. p. 77). Para tanto, preocupado em evitar os abusos, e a contaminação dos negócios públicos por interesses privados, que viciam todas as formas de governar, ocupou-se em estabelecer modos de governar que permitissem o exercício do poder por todos por crer que somente a vontade de todos pode reger um estado. (ROUSSEAU, 2010. p. 33).

Ainda tem grande atualidade o pensamento do genebrino sobre a igualdade entre os homens: "nos maus governos é aparente e ilusória essa igualdade, que só serve para manter na miséria o pobre e o rico na sua usurpação. De fato, as leis são sempre úteis aos que possuem, e danosas aos que nada tem, donde se deduz que o estado social só é vantajoso aos homens quando todos eles tem alguma coisa e quando nenhum deles tem demais." (ROUSSEAU, 2010. p. 31).

Maurizio Virolli aponta a importância da virtude civil para refrear os cidadãos viciosos: "sem cidadãos dispostos a ser vigilantes, a empenhar-se, capazes de resistir contra os arrogantes, servir ao bem público, a república morre, torna-se um lugar em que alguns dominam e outros servem." (BOBBIO. 2002. p. 16).

Desse modo, o mandamento da igualdade e o dever cívico de estruturação do estado em prol do bem comum indicariam que uma comunidade política deve fomentar o equilíbrio entre suas gentes, e deve fazê-lo, direcionando bens essenciais àqueles que não conseguem alcançá-los com suas próprias forças.

O mandamento de igualdade é inerente à concepção de democracia. Os cidadãos nunca estarão em iguais condições de exercer livremente seus direitos políticos se entre eles houverem diferenças de acesso a bens da vida, como educação, saúde, trabalho, moradia. A luta da sobrevivência de uns e a relativa paz social de outros prejudicaria o desenvolvimento igualitário das sociedades políticas e colocaria os marginalizados em situação de vulnerabilidade política.

Como discutir em igualdade de condições as necessárias melhorias sociais se um grupo quer ter mais variedade no prato enquanto que outro só quer ter o quê comer?

Os estados modernos - em qualquer modelo liberal, ou social - mantêm-se com recursos públicos arrecadados daqueles que pagam tributos. A diferença entre um e outro reside na destinação dos recursos públicos arrecadados. No modelo Liberal, aqueles que pagam tributos (as pessoas que tem renda, propriedades ou exploram atividades que geram lucro) estão interessados em que os recursos arrecadados pelo Estado se revertam em seu favor, querem ônibus na porta das suas lojas, boas estradas para melhor escoarem sua produção, segurança e proteção estatal ao seu patrimônio. Por outro lado, os modelos sociais se orientam a garantir a todos, igualdade de acesso a bens sociais cuja gestão compete ao Estado, ocupam-se em garantir estudo e transporte público de qualidade, moradia, proteger à saúde das mães e garantir condições de desenvolvimento saudável aos bebês.

Ingo Sarlet aponta a influência das doutrinas socialistas na incorporação dos direitos sociais nas constituições do pós guerra, em resposta às demandas sociais por um estado ativo na condução e garantia de direitos essenciais ao homem, o que se convencionou chamar de direitos de segunda dimensão (SARLET, 2005, p. 55, 56). Em interessante passagem, o autor ressalta: "estes direitos fundamentais, no que se distinguem dos clássicos direitos de liberdade e igualdade formal, nasceram 'abraçados ao princípio da igualdade', entendida esta num sentido material”' (SARLET, 2005, p. 56).

O direito à saúde, encontra-se previsto no artigo 196 da Constituição Federal de 1988, que prevê: "A saúde é direito de todos e dever do Estado, garantido mediante políticas sociais e econômicas que visem à redução do risco de doença e de outros agravos e ao acesso universal e igualitário às ações e serviços para sua promoção, 
proteção e recuperação."

Esse comando constitucional, segundo as posições pessoais de cada um, poderia ser interpretado de acordo com uma ou outra concepção de Estado. No entanto, não nos parece razoável e justificável sob o ponto de vista da filosofia da história dos direitos humanos (BOBBIO, 2004), continuar a defender uma interpretação alinhada a um modelo Liberal de Estado. Para nós esta forma de interpretar não guarda validade formal com a Carta Constitucional atual, já que tem como consequência a perpetuação da exclusão das massas dos bens sociais ao mesmo tempo em que defende uma melhoria das condições de vida da classe pagadora de impostos.

$\mathrm{O}$ dever de promoção o bem estar de todos - como correlato ao valor democrático já constitucionalizado - implica a necessidade de conhecer aqueles que estão em situação de desigualdade a fim de promover ações direcionadas a reduzir tais desigualdades com o objetivo final de atingir igualdade real entre os cidadãos.

Esse mandamento não pode ser visto como exclusividade do Executivo. É claro que este poder, como executor dos mandamentos constitucionais e legais, deve, de forma mais acentuada, saber localizar as expressões da desigualdade no tecido social a fim de direcionar à atuação administrativa para a sua redução. No entanto, a atuação de cada um dos poderes sempre se manifesta em concreto - artigo 37, caput e artigo $5^{\circ}$, LX, $\mathrm{CF} / 88$ - seja sob a forma de atos administrativos, assim como por atos legislativos ou por decisões judiciais, o que permite que cada um dos poderes tome conhecimento sobre a atuação dos outros. Se o cumprimento deste dever for mal exercido, o dever de fiscalização resultará prejudicado e a democracia, e o equilíbrio entre os poderes, enfraquecidos.

Ao lado da interpretação que se defende, de um estado de direito formalmente democrático e social, os poderes e as instituições que promovem a concretização dos comandos constitucionais necessitam também estar imbuídos dos valores constitucionalmente consagrados para que a concretização de direitos, e nesse particular dos direitos sociais, seja realizada e alcancemos uma sociedade mais equânime.

Sob esse ponto de vista, a melhoria capaz de distribuir acentuadas vantagens de saúde a pessoas que já tem garantido esse direito, seja do sistema público ou no privado, seria justificável se não houvesse mais necessidade de garantir o mínimo - poderíamos dizer que o simples acesso seria o mínimo - aqueles que se encontram à margem do sistema.

Logo, não seria democraticamente sustentável conceder um plus a uma camada da população enquanto houver pessoas totalmente a margem do sistema. A distribuição do acréscimo de saúde não deve coexistir com a ausência de prestação de saúde. ${ }^{1}$

Oposta a esta posição, aqui defendida, está o ponto de vista daqueles que entendem que se há alguém pleiteando em juízo um medicamento e se este medicamento é o mais adequado para o tratamento da moléstia que acomete esta pessoa, o Judiciário deve garantir o seu recebimento. Para este posicionamento não importa se a demanda surge de um médico particular ou se existem outros tratamentos para a doença disponibilizados nos protocolos do SUS. O raciocínio é: se existe o melhor e se a pessoa necessita deste "melhor", o Judiciário deve garanti-lo.

Há, claramente, uma acentuada diferença entre esses posicionamentos. O primeiro deles, que aqui se defende, procura garantir o acesso à saúde - bem estar - a todos, enquanto que o segundo quer o melhor tratamento para um paciente, sendo certo que o melhor tratamento é um conceito vago, somente aferível no caso concreto.

No entanto, talvez, a maior diferença resida no fato de que o primeiro posicionamento é incapaz de refrear os arbítrios, justificar e racionalizar os gastos públicos e conter a internalização de interesses privados.

As carências e insuficiências do SUS necessitam ser identificadas e corrigidas. No entanto esta correção necessita ser realizada para todos. Ainda que se argumente a 
justiça do primeiro posicionamento, ela somente serve a um interesse individual, o que, queremos crer, não pode ser validamente oponível a toda a coletividade.

Para Fernando Facury Scaff, a judicialização da saúde realizada nesses moldes não deseja garantir direitos sociais efetivando políticas públicas, mas sim procura garantir direitos individuais com recursos públicos, uma concessão de medicamentos que não são oferecidos a todos os cidadãos. (NUNES, 2011, p. 109).

\section{3 - Separação de poderes: contornos constitucionais}

As reformas constitucionais do pós guerra no século XX tiveram como resultado a constitucionalização de valores socialmente relevantes em resposta aos clamores sociais de construção de um aparato jurídico capaz de resistir a abusos e refrear eventuais tentativas de desvirtuar a organização do estado. Nesses valores, além dos já mencionados direitos sociais, queremos inserir a necessidade de separação de poderes. As sociedades que experimentaram períodos de exceção necessitavam se proteger contra o arbítrio estatal e afirmar os valores reais do Estado - a realização do bem comum - a fim de se defender contra a prepotência e a opressão.

A constitucionalização do equilíbrio e separação de poderes assume uma acepção social nas cartas do pós-guerra manifestando-se, por um lado, como a necessidade de coibir o exercício arbitrário de qualquer um dos poderes e evitar que a atuação de um possa oprimir o livre exercício de outro, pois o desequilíbrio entre essa relação tem como principal efeito perverso a opressão aos diretos do homem.

Por outro lado, a constitucionalização de tais valores assume também conteúdo político, manifestando-se como a instituição de um modelo de estado que se orienta para um fim social, em oposição aos experimentados estados de exceção em o interesse social de abolição da figura de estado em que se movimentou a maquina estatal em benefício de grupos privados, perseguindo cidadãos e restringir a liberdades fundamentais.

As sociedades que ultrapassaram esse período sombrio necessitavam que o Estado fosse renovado, alterando radicalmente o cenário opressor. Clamava-se por uma configuração de Estado que se afirmasse positivamente, para efetivar e implementar os direitos sociais, rompendo definitivamente com nas sociedades que ainda se recuperam dos obscuros cenários ditatoriais de violações de direitos.

Apoiamo-nos em Post e Siegel para defender que a interpretação constitucional ${ }^{2}$ deve se dar de forma democraticamente accountable, embasada nas crenças compartilhadas da sociedade. A posição defendida por esses autores questiona a crença na autoridade da "voz judicial" na interpretação do texto constitucional. Os autores argumentam que a interpretação constitucional de valores compartilhados pelo povo deve refletir as crenças dos cidadãos, para que sejam democraticamente responsivas. Uma violação a esse statement feriria a legitimação democrática da lei constitucional e causaria backlash negativo à decisão sobre a matéria constitucional.

Em The Least Dangerous Branch, Bickel afirma que quando a constituição se dirige expressamente a um poder em particular, conferindo-lhe, diretamente, atribuições ou competências, deve ser deste poder a prerrogativa de avaliar qual o sentido do comando que lhe é dirigido. ${ }^{3}$.

Para o autor, os mandamentos constitucionais emanam diretamente aos seus intérpretes: população, poderes constituídos e instituições de estado. Quanto aos comandos que se referem diretamente a cada um dos poderes, cada um dos poderes, ao exercer suas funções deve promover a obediência e a atuação conforme a Constituição.

A esse respeito, a concretização de igualdade e justiça, na medida em que são também valores inscritos no texto constitucional - art. $3^{\circ}$, I e III, CF/88 - são, portanto, 
incumbência de todos os poderes e instituições do Estado.

Seguindo este raciocínio, não se pode admitir que seja do Judiciário o monopólio da realização da justiça social. O próprio Supremo Tribunal Federal, em voto da Ministra Carmem Lúcia (STF, ADI 2.649), já afirmou que o preâmbulo da Constituição explicita os valores que dominam a obra constitucional de 1988 e, com amparo na doutrina de José Afonso da Silva, defendeu que o Estado Democrático de Direito se conforma para assegurar a observância aos valores supremos, conforme elencados no preâmbulo.

A democracia, portanto, além de valor político e garantia conferida aos cidadãos também é valor que deve emanar no exercício dos poderes e no relacionamento entre eles. Isso significa dizer que dada a divisão das funções de estado em poderes e instituições diversas cada uma das funções tem, além das incumbências diretas conferidas pelo texto constitucional, o dever de acompanhar o exercício das típicas dos outros poderes.

De igual forma, afinados com o pensamento de Bickel, não se pode conferir com exclusividade ao Judiciário a prerrogativa de interpretar os comandos constitucionais. Essa idéia seria completamente contrária ao necessário equilíbrio entre os poderes, conferiria acentuada vantagem o judiciário, que, tendo a prerrogativa interpretativa, poderia livremente interferir no exercício dos outros poderes. Além disso, não seria razoável condicionar o cumprimento dos mandamentos constitucionais a necessidade de interpretação judicial sobre o tema.

A guarda da constituição, conforme o próprio texto constitucional - art. 102, caput, CF/88 - cabe "precipuamente" ao Supremo Tribunal Federal. Por outro lado, confere-se a prerrogativa constitucional do Judiciário de dizer a respeito da validade dos atos normativos - art. $5^{\circ}, \mathrm{XXXV}, \mathrm{CF} / 88$ - e aos Tribunais Superiores - art. 102, III CF/88 e artigo 105, III, $\mathrm{CF} / 88$ - a decisão final sobre sua validade. Com isso resta aos demais intérpretes a justa expectativa de que o Judiciário realize o controle constitucional dos atos normativos e administrativos que exorbitem sua validade.

Com isso, delineia-se o cenário constitucional de conformidade e organização formal do sistema jurídico brasileiro, no qual a constituição é o fundamento último de validade, determinando a homogeneidade do sistema legal, impondo-se que a organização do estado, a conformação de seus poderes e de suas instituições se deem em respeito às normas constitucionais.

Nesse sentido, a constituição atribui ao Legislativo a concretização do direito à saúde no plano infraconstitucional - artigos 23, II, V, IX, 24, IX, XII e 30, VI, VII, $\mathrm{CF} / 88$ - e encarrega o Executivo de realizar a distribuição dos bens sociais in concreto, ao mesmo tempo em que impõe que essa distribuição atenda a critérios de impessoalidade e eficiência - artigo 37, caput, $\mathrm{CF} / 88$. Por isso, os atos normativos infraconstitucionais e infralegais editados para o cumprimento dos comandos constitucionais devem ser impessoais, dando igual tratamento a todos aqueles que se encontrem na mesma situação.

Dessa forma, a respeito do fornecimento de medicamentos no Sistema único de Saúde, o sentido da "integralidade" de tratamento foi definido por lei federal - Lei 12.401, alterou a Lei $\mathrm{n}^{\circ} 8.080$ e passou a viger em todo o território nacional em 28 de outubro de 2011 - que definiu e regulou o direito ao recebimento gratuito de medicamento no âmbito do SUS, relacionando-o à prescrição médica estiver em conformidade com as diretrizes terapêuticas previstas em protocolo clínico para o tratamento da doença.

A mesma lei fixou a atribuição do Ministério da Saúde - com o assessoramento da Comissão Nacional de Incorporação de Tecnologias do SUS - para a inclusão de novos medicamentos nos protocolos clínicos, bem como a constituição ou a alteração de protocolo clínico. ${ }^{4}$ 
Nos termos da lei, o medicamento novo será incorporado aos protocolos SUS se restar comprovada, ao mesmo tempo, cientificamente a eficácia, acurácia, efetividade e segurança do medicamento e se comparativamente aos medicamentos já disponíveis o novo medicamento se mostrar economicamente viável, vantajosa ou equitativa quanto às drogas já existentes.

Dessa forma, ao contrário do que pode parecer, o processo de incorporação de novos medicamentos nos protocolos do SUS é um processo sério e que se submete a regras legais pré-estabelecidas, de modo a permitir a qualquer momento o controle social e judicial.

De qualquer modo, os pareceres sobre a incorporação de medicamentos no sistema SUS, são atos administrativos complexos exarados por profissionais especializados no âmbito do Ministério da Saúde. Tais pareceres costumam ter a participação de experts em farmacologia e em medicina.

Por ocasião da audiência pública de saúde realizada no Supremo Tribunal Federal no ano de 2007, foi apresentado o impacto estimativo que a incorporação de medicamentos de última geração prescritos para o tratamento de apenas duas doenças geraria se tais medicamentos fossem incorporados do sistema SUS para distribuição a todos os doentes em iguais condições. A incorporação dessas drogas (interferon peguilato para hepatite viral crônica $\mathrm{C}$ e infliximabe, etanercepte e adalimumabe indicados para artrite reumatóide) custaria 99 bilhões de reais aos cofres públicos, superando todo o orçamento da saúde. (SANTOS, 2010, p. 136).

Como dito, a própria lei fixa os critérios e delimita a atuação do administrador para a dispensação de medicamentos no âmbito do SUS - se realizará nos termos dos protocolos clínicos - e ainda prevê como deverá ser a atuação no caso de insuficiência de protocolos.

Os protocolos de dispensação de medicamentos, por sua vez, não apenas existem como são reeditados com relativa freqüência para incluir novas patologias ou alterar a listagem de medicamentos.

Deste modo, a consecução das políticas pública de dispensação de medicamentos no âmbito do SUS está devidamente realizada no aspecto formal quanto às competências do Legislativo e do Executivo.

Portanto, havendo regra específica aplicável ao caso, cabe ao Judiciário aplicála. Do contrário, na lição de Luiz Roberto Barroso, coloca-se em risco a legitimidade democrática, pois entre o legislador e o juiz, as escolhas desse primeiro é que devem prevalecer. (BARROSO, 2008).

Quanto às capacidades institucionais de cada um dos poderes, o Poder Judiciário manifesta-se em concreto nas sociedades através do processo que obedece a regras, ritos e prazos próprios com o objetivo final de se chegar a uma decisão (de mérito ou não) que resolva a lide. Os prazos legais a que o processo judicial se submete impedem o aprofundamento das discussões técnicas, por exemplo, aquelas que envolvem o processo de incorporação de medicamentos nos protocolos do SUS.

A expertise do Executivo, por outro lado, deve ser a de executar as leis criadas pelo Legislativo no exercício de sua competência constitucional e editar atos normativos ao fiel cumprimento destas normas. O espaço de atuação do Executivo, por outro lado, embora deva ser vinculado à lei, é mais amplo. A atuação administrativa se obriga a ser eficiente, e para tanto precisa ser racionalizada, evitando o desperdício de recursos públicos. Para que esta atuação seja efetiva e pontual impõe-se ao Executivo mais gravemente o conhecimento da sociedade que governa, e ele comumente sabe onde estão as áreas carentes de políticas públicas porque habitualmente faz parte das estratégias de campanha política percorrer as zonas eleitorais para buscar votos.

Estruturalmente, o Judiciário é um poder inerte e mais "sedentário", o Estadojuiz só se manifestará quando provocado, enquanto que o Executivo é um poder 
dinâmico, deve conhecer a sociedade para a qual executará as normas legais.

Muito embora se tente corrigir essa característica da Justiça, com a instituição de justiça itinerante - artigo 107, $\S 2^{\circ}$ e artigo125, $\S 7^{\circ}, \mathrm{CF} / 88$, inseridos pela Emenda Constitucional $n^{\circ} 45 / 04$ - por exemplo, e a determinação de que os magistrados residam na comarca ou seção judiciária em que atuam - artigo 93, VII, CF/88 - fato é que os juízes, em grande parte, conhecem a sociedade através dos autos que lhe chegam a conhecimento.

Fernando Scaff aponta as balizas jurisprudenciais criadas pelo STF após a realização da referida audiência pública e cita as conclusões do Ministro Gilmar Mendes ${ }^{5}$ sobre a questão de fornecimento de medicamentos por entes públicos. Neste ponto, julgamos elucidativo trazer a sistematização realizada pelo autor (NUNES, 2011, p. 123) sobre as diversas espécies de situações que podem surgir na dispensação de medicamentos pela via judicial.

Assim, seria necessário distinguir os casos em que há política para a dispensação de medicamentos e recusa ilegal da Administração em conceder, ou se a prestação de saúde se refere a uma omissão legislativa ${ }^{6}$.

No primeiro caso, a recusa injusta necessita ser corrigida, dando-se o fiel cumprimento à lei. Não haveria, nesse caso, interferência do poder Judiciário nas políticas públicas de saúde, mas apenas determinação judicial para o cumprimento.

Por outro lado, a segunda hipótese, pode envolver situações em que há omissão legislativa ou administrativa, recusa expressa da Administração ou vedação legal à dispensação (hipóteses em que o medicamento não é registrado pela ANVISA).

Scaff cita o entendimento firmado no Tribunal quando houver protocolo clínico. Neste caso, o ente público somente poderia ser compelido a fornecer os medicamentos previamente prescritos nas políticas públicas. Ressalvou-se, é claro, a possibilidade de demonstração da ineficiência dos medicamentos pré-estabelecidos, o que já poderia ser entendido como inerente à competência constitucional prevista pelo artigo $5^{\circ}, \mathrm{XXXV}$, $\mathrm{CF} / 88$.

Por outro lado, afirmou-se o entendimento de o Estado latu sensu não poder ser obrigado a custear tratamento com medicamento experimental ou não aprovado pela ANVISA.

Por fim, quanto à hipótese de ausência de protocolo clínico firmou-se a impossibilidade de violação ao direito à saúde e a possibilidade de impugnação judicial “'tanto por ações individuais como por ações coletivas' sendo necessário que haja a instrução probatória, o que certamente se configurará em um obstáculo à concessão de cautelares" (NUNES, 2011, p.124)

Com o advento da lei 12.401 de 2011, eventual ato normativo que recuse medicamento por ausência de protocolo seria considerado um ato ilegal em razão da norma prevista no artigo 19-P, da Lei 8.080/90.

Em outra ocasião, instado a se manifestar sobre decisão que determinou o fornecimento de medicamento por ente público, o STF, fixou o entendimento de que para fins de comprovação da necessidade e demonstração da hipossuficiência do demandante, é necessário que o paciente apresente receita médica formulada por médico do Sistema Único de Saúde (STF, STA 334 AgR/SC. STF, STA 328 AgR/PR.)

Como se vê, o entendimento esposado na Corte Constitucional se adequa perfeitamente aos mandamentos legais da Lei 8.080/90.

Uma questão muito frequente que ainda não foi enfrentada pelos Tribunais Superiores refere-se ao pedido judicial de medicamento integrante da lista de dispensação excepcional que se insere na competência dos estados formulado em face do Município. Nesse aspecto o ato administrativo que atesta que o medicamento deve ser solicitado na farmácia especializada é formalmente válido, porque atende aos limites de competências definidas pela lei. Nessas demandas, frequentemente, o judiciário 
impõe que o Município compre o medicamento gratuitamente fornecido pelo Estado e disponibilize ao interessado.

Analisados os parâmetros legais e os fixados pela Corte Constitucional nos resta verificar, na próxima parte do trabalho, como o Tribunal Mineiro decide as demandas relativas à dispensação de medicamentos, o que faremos ao analisarmos as decisões oriundas das comarcas de maior desproteção social do estado.

4 - Pesquisa jurisprudencial

4.1 - Metodologia

A fim de avaliar a frequência, o contingente e o conteúdo das decisões proferidas pelo Tribunal Mineiro em comarcas de alta desproteção social quanto à matéria do fornecimento de medicamentos, parte deste trabalho consistiu em uma pesquisa jurisprudencial, realizada por intermédio das ferramentas de busca disponibilizadas pelo Tribunal de Justiça de Minas Gerais em seu próprio site.

Diante das limitações impostas pela pesquisa, optamos por avaliar as decisões de segundo grau oriundas de cinco comarcas do Estado de Minas Gerais, selecionadas sob os critérios de índice de desenvolvimento humano bem como de desproteção social.

Para a escolha das comarcas utilizou-se a combinação de dois parâmetros, o Índice de Desenvolvimento Humano e os mapas de desproteção social, indicador de emprego e renda, distribuição da proporção de pessoas pobres. Localizada a região e as cidades mais carentes, fizemos o cruzamento com o mapa das comarcas mineiras, para a seleção das comarcas.

Os mapas de indicativos sociais foram extraídos do Relatório de Atividades do Observatório de Desenvolvimento Social, produzido pela Secretaria de Estado de Desenvolvimento do Estado de Minas Gerais, a fim de avaliar a efetividade das políticas públicas implementadas, com o objetivo de orientar a implementação de futuras políticas públicas e identificar as áreas ainda carentes de maior atenção.

Para a elaboração do relatório social o Estado de Minas Gerais foi dividido em dez regiões. Selecionamos comarcas das regiões que apresentaram maior grau de desproteção social que foram as regiões do Vale do Jequitinhonha, norte, noroeste do estado. Optou-se, intencionalmente por regiões mais distantes dos grandes centros urbanos que tem menor cobertura viária e reduzido acesso a bens e serviços.

Segundo o Programa das Nações Unidas para o Desenvolvimento, o Índice de Desenvolvimento Humano, é uma medida de desenvolvimento social relativa à população de uma comunidade política. Esse índice foi criado para se contrapor ao Produto Interno Bruto, que é um medidor de riqueza de um território geográfico determinado. $\mathrm{O}$ IDH leva em conta o desenvolvimento das sociedades quanto à saúde, educação e renda das pessoas que compõem uma dada sociedade ou território.

Este índice varia entre grandezas numéricas expressadas entre 0.799 e 0 . As faixas de variação de IDH são: de 0 a 0,499, IDH muito baixo; de 0,500 a 0,599, IDH baixo; 0,600 a 0,699, IDH médio e, por fim, de 0,700 a 0,799, IDH alto.

Assim, selecionamos decisões provenientes das comarcas de Januária, Buritis, Jequitinhonha, Araçuaí e Novo Cruzeiro, regiões mais carentes de acordos com os parâmetros aqui avaliados.

Segundo a lei de organização judiciária do Estado as comarcas muitas vezes englobam o território de mais de um município, sendo assim consideramos importante pontuar as características das cidades pertencentes às de das comarcas objeto de estudo, a fim de que se possa conhecer a extensão geográfica em análise e suas características sociais ${ }^{7}$.

No norte de minas, selecionamos a comarca de Januária, cuja cidade sede tem 
IDH 0,699, PIB per capita R 4861,22 , e população ${ }^{8} 67$ mil habitantes e engloba, além da cidade sede, as cidades de Bonito de Minas, IDH 0,537, Cônego Marinho, IDH 0,621, Pedras de Maria da Cruz, IDH 0,614 e Itacarambi, IDH 0,641.

No noroeste do estado, escolhemos Buritis que tem IDH 0,672, PIB per capita R\$ 16 647,80 e população de aproximadamente 23 mil habitantes. A comarca abarca também a cidade de Formoso, que tem IDH 0,640.

Todas as três comarcas restantes foram oriundas da região do Jequitinhonha, a mais carente do estado.

A cidade de Jequitinhonha tem IDH 0,668, PIB per capita $\mathrm{R} \$ 4$ 327,41, população 24 mil habitantes. Na circunscrição da comarca estão também as cidades de Monte Formoso, IDH 0.541, Joaima ${ }^{9}$ e Felisburgo, IDH 0,583.

A comarca de Araçuaí, tem IDH 0,663, PIB per capita R\$ 6 193, 85, população 37 mil habitantes e compreende as cidades de Coronel Murta, IDH 0,627, Virgem da Lapa, IDH 0,610, Itinga, IDH 0,600, Ponto dos Volantes, IDH 0,595, Padre Paraíso, IDH 0,596.

Por fim, Novo Cruzeiro, a mais pobre das comarcas, tem IDH 0,629, PIB per capita R\$ 3279,70 e população 31 mil habitantes e engloba, além da cidade sede, as cidades de Caraí, IDH 0,558, Itaipé, IDH 0,552 e Catuji, IDH 0,540.

A pesquisa procurou pelos termos "fornecimento" e "medicamento" de forma conjunta. Os resultado global encontrado, ou seja, o total das decisões proferidas em todo o estado para este parâmetro de busca, pode incluir decisões em que apenas um dos termos foi encontrado. Deste modo, a pesquisa pode abranger alguns desníveis.

Do resultado final selecionado foram retiradas as decisões que não corresponderam ao objeto pretendido. A margem de erro foi na ordem de $13 \%$.

A busca foi realizada a partir da data de publicação dos acórdãos e compreendeu o período de primeiro de janeiro de 2000 (dois mil) a 31 (trinta e um) de dezembro de 2013 (dois mil e treze).

\section{2 - Resultados}

O resultado da pesquisa permitiu constatar que a distribuição de medicamentos pela via judicial em Minas Gerais é fenômeno relativamente recente. A análise das decisões proferidas em segundo grau nos mostra que as primeiras decisões sobre a matéria foram proferidas no ano 2000. Após esse ano o número de decisões foi aumentando gradativamente até atingir o máximo de 2.667 (duas mil seiscentas e sessenta e sete decisões) no ano de 2011. Depois de 2011, verificou-se uma pequena redução no montante global de decisões encontradas.

A razão entre o somatório de decisões encontradas para todo o estado e o numero de cidades apresentou a proporção de 18,49 decisões por cidade mineira ${ }^{10}$. 


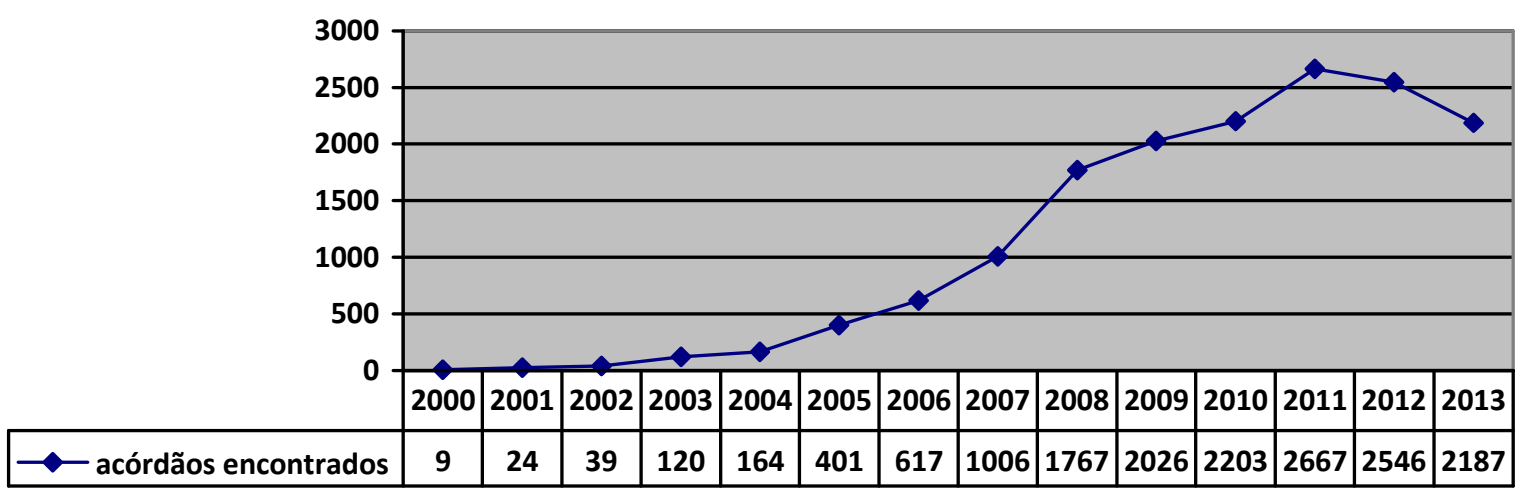

Quanto ao resultado específico sobre as comarcas alvo da pesquisa não foi encontrado nenhum acórdão referente às comarcas de Novo Cruzeiro, Jequitinhonha e Buritis.

A pesquisa encontrou 12 decisões oriundas da comarca de Januária e apenas 3 decisões provenientes da comarca de Araçuaí.

Com isso a região do vale do Jequitinhonha, a mais pobre e também a maior área territorial selecionada, apresentou apenas três resultados.

A região noroeste do estado também ficou de fora do fenômeno da concessão judicial de medicamentos.

Analisando-se o resultado por cidades, temos que na região norte, para 5 cidades foram encontradas 12 decisões enquanto que no vale do Jequitinhonha, para um território de pesquisa que compreendeu 15 cidades foram obtidas 3 decisões de segundo grau.

Comparativamente, em todo o período pesquisado foram encontrados 15.776 acórdãos para os termos de pesquisa "fornecimento" e "medicamento", assim, o resultado obtido representa $0,095 \%$ do total.

A pesquisa compreendeu 21 cidades, das 853 (oitocentas e cinquenta e três), e a amostra da pesquisa correspondeu a $2,46 \%$ das cidades mineiras.

Quanto ao resultado obtido para a comarca de Januária, das doze decisões encontradas uma foi publicada em 2008, duas em 2011, três em 2012 e seis em 2013.

Em três decisões o tribunal extinguiu a ação (mandado de segurança) por falta da comprovação da necessidade do medicamento e da negativa do Município em fornecer.

Em todas as decisões as obrigações se referiram a medicamentos mais comuns e de médio custo, variando em torno de $\mathrm{R} \$ 25,00$ (vinte e cinco) a $\mathrm{R} \$ 230,00$ (duzentos e trinta reais) mensais.

Somente uma decisão destoou do resultado geral encontrado, na qual houve também a obrigação de fornecer de alimento especial (nutrição enteral ou parenteral). Neste caso, houve utilização de verbas públicas (após descumprimento de decisão e determinação judicial de bloqueio de verbas) no valor de $\mathrm{R} \$ 3.200,00$ para aquisição direta dos produtos pleiteados. ${ }^{11}$

Não houve manifestação judicial acerca da insuficiência de recursos dos demandantes, todavia, o valor relativamente baixo dos medicamentos e a provocação judicial já seria suficiente para sugerir ao órgão julgador a hipossuficiência e a necessidade da dispensação gratuita.

Não obstante tratarem-se de demandas simples para as quais normalmente existe política pública estabelecida, não houve manifestação do Tribunal sobre os protocolos clínicos do SUS ou sobre a possibilidade de utilização de medicamento alternativo disponibilizado gratuitamente seja pela farmácia básica do Município ou 
pela Secretaria de Estado e Saúde. Tampouco houve manifestação sobre as normas previstas na Lei Federal $n^{\circ} 8.080$ para a dispensação de medicamentos no sistema SUS.

Quanto às decisões encontradas oriundas da comarca de Araçuaí, todas as três decisões foram publicadas no ano de 2013.

Pudemos observar com relação a essa comarca que o critério utilizado para a concessão do medicamento foi o laudo médico pelo médico da paciente atestando a necessidade do medicamento, o que o Tribunal considerou como prova inequívoca na necessidade de determinação judicial. Não houve manifestação acerca da hipossuficiência alegada em juízo.

As determinações judiciais se referiram ao fornecimento de medicamentos para o tratamento de epilepsia, diabetes e câncer. Para todas essas doenças existe protocolo clínico do SUS, não obstante não houve manifestação do tribunal sobre essa matéria.

Igualmente, não houve manifestação sobre as normas previstas na Lei Federal $\mathrm{n}^{\circ} 8.080$ para a dispensação de medicamentos no sistema SUS.

$\mathrm{O}$ caso mais grave foi referente à concessão de medicamento para o tratamento de câncer hepático com metástase de abdome, doença em estágio IV ${ }^{12}$, no qual houve determinação judicial para que o Município de Itinga fornecesse o medicamento Malato Sutinibe $50 \mathrm{mg}$, de custo estimado em R\$ 18.850,00 (dezoito mil, oitocentos e cinquenta reais). ${ }^{13}$

Nos outros dois casos o Estado de Minas Gerais foi coréu, juntamente com o ente municipal.

No resultado final da pesquisa, observamos que em todas as decisões encontradas o direito discutido em juízo foi um direito individual, e, em todas elas, nada se falou sobre os protocolos clínicos do SUS. Não se mencionou, concretamente, sua ineficiência - quando existe protocolo mas este não abrange tratamentos adequados para a pessoa - nem sua insuficiência - quando não existisse protocolo para tratamento da doença.

O principal argumento encontrado nos acórdãos para a concessão dos medicamentos foi o de que o artigo 196 da CF/88 institui norma autoaplicável de caráter pragmático. Afirmou-se também que o mesmo artigo determina o dever de o estado prestar integralmente o tratamento que for necessário para a manutenção da saúde e da vida digna.

A pesquisa constatou que as demandas sobre concessão de medicamentos pela via judicial são amplamente demandas individualizadas, não foram encontradas ações coletivas com pedidos extensivos a toda a população, nem mesmo ações coletivas visando questionar os medicamentos incluídos nos protocolos SUS ou buscando a inclusão de novos medicamentos em tais protocolos.

Verificou-se também que para o Judiciário "conceder" o medicamento pedido pela parte com recursos orçamentários de outro poder, bastou a apresentação da receita médica. A análise judicial restringiu-se à afirmação da necessidade do medicamento conforme alegação da parte, sem tecer qualquer justificação sobre aos diplomas legais que instituem os protocolos clínicos para tratamento da doença relacionada ao medicamento pleiteado ou mesmo justificar porque lhes nega vigência.

Assim, o resultado final tem pouquíssima expressividade quando comparados com o montante das decisões proferidas sobre o tema no estado, isso significa dizer que o alto grau de desigualdade e desproteção social das comarcas alvo da pesquisa teve pouquíssima relevância para a judicialização do fornecimento de medicamentos.

Essa desproporcionalidade entre situação de desproteção social e a pouca (ou nenhuma) expressividade de decisões provenientes dessas regiões, pode indicar que o sistema de dispensação de medicamentos disponibilizado pelo SUS funciona para essas populações no aspecto aqui estudado.

Restou, portanto, comprovado através da pesquisa que onde os pobres estão não 
ocorre judicialização da saúde. Logo, não se pode afirmar, validamente, que o Judiciário ao interferir nas políticas públicas de dispensação de medicamentos, está promovendo justiça social e democratizando a saúde.

\section{5 - Considerações finais}

O resultado da pesquisa nos permite concluir que o Judiciário, conforme aponta Bickel, no campo das ações de distribuição de medicamentos nega observância à sua própria competência constitucional e à do Legislativo e Executivo. Nem mesmo as leis, as orientações jurisprudenciais do STF e as recomendações do CNJ são levadas em consideração pelo judiciário mineiro ao decidir sobre a concessão de medicamentos.

Em vista disso, comprova-se que a expertise do poder judiciário são normas jurídicas, de modo que não se pode esperar do juiz a capacidade de avaliar racionalmente questões técnicas de saúde que envolvem escolhas racionais administrativas realizadas por profissionais de farmácia, bioquímica, saúde pública, administração pública, entre outras áreas do conhecimento.

Assim, constata-se que nem é o processo judicial o meio adequado para se realizar discussões de questões que envolvem temas de grande complexidade e demandam conhecimento técnico interdisciplinar - como farmacologia, medicina - nem é o Judiciário o poder com melhor capacidade institucional para avaliar tecnicamente as questões de política de saúde, sobretudo no processo individual. A transferência do fórum de discussão de políticas públicas do executivo para o processo judicial é, assim, estruturalmente inviável.

Não se pretende retirar a competência constitucional dos órgãos judiciários de proceder ao controle judicial dos atos administrativos, o que, de fato, sequer é realizado. $\mathrm{O}$ que se pretende esclarecer é que a concretização da competência constitucional prevista no artigo 196, da CF/88 foi plenamente exercida pelos demais poderes, e envolve atos normativos e pareceres técnicos relevantes e específicos para cada doença, que o juiz não tem capacidade técnica para discutir.

Justamente por esta razão, incapaz de formar seu convencimento segundo os critérios estabelecidos pelo sistema jurídico e por normas que desconhece, diante do dilema moral que a questão traz para o julgador faz-se a opção pelo argumento do direito à vida e o princípio da dignidade da pessoa humana, concretizando diretamente normas jurídicas, caso a caso, quando é certo que as regras jurídicas expressas aplicáveis ao caso permanecem vigentes e válidas.

Faticamente, garantir o acesso de medicamento àqueles que batem as portas do judiciário é uma escolha pontual que não implica, necessariamente, num incremento da saúde daqueles que realmente precisam ou mesmo daqueles que se encontram em iguais condições.

Todavia, talvez, o grande problema deste cenário seja que o vilipêndio das normas constitucionais não atinge resultado efetivo para a redução das desigualdades sociais.

A judicialização da saúde, assim, mimetiza perfeitamente as estruturas sociais excludentes da sociedade brasileira, na qual, com efeito, o pobre não é preocupação do judiciário, é acidente de percurso.

O poder burguês, formado e mantido por burgueses também se presta a atender a interesses burgueses e se aperfeiçoa, para transferir os recursos públicos para a melhoria desta classe.

Mais uma vez a falácia argumentativa liberal do poder Judiciário se presta a servir a interesses estranhos aos deveres de redução das desigualdades sociais e promoção de uma sociedade mais equânime. Se a região mais pobre do estado tem tão 
pouca participação no fenômeno de promoção de justiça social defendido pelo Judiciário, é forçoso concluir que o Judiciário apenas prejudica a prestação de serviços de saúde para os reais usuários do sistema.

Por fim, realizar a justiça social para quem não precisa é aumentar as desigualdades sociais, fazer a vida do rico cada vez melhor e a vida do pobre cada vez mais esquecida.

\section{6 - Notas}

${ }^{1}$ Usando uma analogia com a geografia, quanto mais o relevo é elevado mais distante ele está com relação ao nível do mar. Considerando o pico como o resultado ótimo, e o nível do mar como a ausência de resultados, o ponto equânime seria o ponto mediano entre essas extremidades, o pico e o nível do mar. Desse modo um aumento na altitude, que levasse ao aumento do pico com relação ao nível do mar, deveria, necessariamente, corresponder a um aumento de mesma proporção no nível mais baixo do relevo somente para que se mantivesse a equanimidade entre os pontos equidistantes. $\mathrm{O}$ incremento do direito à saúde para a população que acessa o judiciário requerendo medicamentos caros deveria corresponder necessariamente a um incremento da saúde da população marginalizada que tem pouco ou nenhum acesso à saúde, do contrário temos um aumento da "distância" entre os "pontos equidistantes". A verdadeira redução de desigualdades seria atingida com a aproximação do ponto mais baixo do relevo ao ponto mediano.

2 Post e Siegel referem-se expressamente à interpretação realizada por Cortes Constitucionais. (POST, SIEGEL. Roe Rage: Democratic Constitucionalism and Backlash.)

3 "And of the legislature as well as of courts, so that when the Constitution addresses itself to the legislature, or to the President, or to the States, for that matter, each may be the final arbiter of the meaning of the constitutional commands addressed to it" (BICKEL, Alexander. The least dangerous branch: the supreme court at the bar of politics. 2. Ed. New Haven: Yale University Press, 1986. p. 7)

${ }^{4}$ Muito conhecido pelos advogados públicos que militam na área de saúde, o protocolo SUS é um documento normativo no qual se encontram relacionadas as doenças e sua correspondente forma de tratamento. No campo da dispensação de medicamentos existe o RENAME, que lista todos os medicamentos integrantes da farmácia básica, cuja distribuição fica a cargo dos municípios. Este protocolo lista as doenças de maior incidência na população. A definição dos protocolos e a distribuição dos medicamentos (mais caros) que compõem o componente especializado ficam a cargo dos estados. Nessa categoria encontram-se os medicamentos indicados para doenças de maior complexidade e, por consequência, com menor incidência. É esperado que os médicos conheçam o protocolo SUS e realizem o tratamento nos termos da política nacional de saúde. A atuação conforme a lei é essencial para o controle e fiscalização das políticas públicas, e para a racionalidade dos processos de compras e controle de estoques.

${ }^{5}$ O Ministro foi o relator do AgRg da STA 175-CE, cuja decisão foi aprovada por unanimidade em composição plena, tornando-se um leading case no tema.

${ }^{6}$ Também se reconhece a possibilidade de o Executivo por meio de portarias incluir medicamentos não padronizados pelo RENAME e não dispensados pelo Estado.

${ }^{7}$ Todas as informações das cidades foram retiradas do Wikipédia.

${ }^{8}$ Todos os valores de população apresentados foram aproximados.

${ }^{9}$ IDH não disponível.

$10 \mathrm{O}$ estado de Minas Gerais possui 853 municípios. http://pt.wikipedia.org/wiki/Anexo:Lista_de_munic\%C3\%ADpios_de_Minas_Gerais 
${ }^{11}$ A determinação de bloqueio de verbas para a aquisição de suplementos de saúde é medida excepcional e não prevista em lei, somente admitida em doutrina quando o descumprimento de decisão judicial puder causar grave dano à saúde da pessoa. No caso não houve informação precisa, todavia, diante da excepcionalidade da medida, da existência de meio executivo próprio previsto em lei e da necessidade de cumprimento da decisão judicial que permanece eficaz, somente se admite que o bloqueio de verbas se refira à necessidade atual, de modo que nos cabe a conclusão de que o bloqueio de verbas se referiu a gastos mensais, se outro não foi o entendimento judicial.

$12 \mathrm{O}$ câncer em estágio IV é considerado avançado e nesses estágios a terapêutica aplicada é de cuidados paliativos, objetivando conter a disseminação da doença e aumentar a sobrevida dos pacientes. (PEIXOTO, I.C.; PEREGRINO, A. A. F., OLIVEIRA, O. V. S.; RAMOS, R. S.. Análise do perfil dos pacientes oncológicos sem possibilidades terapêuticas de cura atuais: verificação da demanda por cuidados paliativos em hospital universitário. Revista Hospital Universitário Pedro Ernesto. 2011; vol. 10, (Supl.1), pp. 53-63. Disponível em: $<$ http://revista.hupe.uerj.br/detalhe_artigo.asp?id=123> Acesso em: 20 mar. 2014.)

${ }^{13}$ Não obstante os juízes costumarem apontar a existência de laudo ou a receita médica provenientes do SUS, a fim de afirmar a necessidade de dispensação do fármaco, a decisão foi omissa quanto a origem do laudo médico. (TJMG, Agravo de Instrumento Cv 1.0034.13.001113-2/001, Relator(a): Des.(a) Edilson Fernandes , 6 ${ }^{\mathrm{a}}$ CÂMARA CÍVEL, julgamento em 19/11/2013, publicação da súmula em 03/12/2013)

\section{7 - Referências Bibliográficas}

AFONSO DA SILVA, Virgílio; TERRAZAS, Fernanda Vargas. Claiming the right to health in Brazilian Courts: The exclusion of the already excluded? Law and Social Inquiry, Forthcoming. 2011.

BOBBIO, Noberto. A era dos direitos. Rio de Janeiro: Elsevier, 2004.

; VIROLLI, Maurizio. Diálogos em torno da república: os grandes tema da

política e da cidadania. Rio de Janeiro: Campos, 2002.

BARROSO, Luis Roberto. Judicialização, ativismo judicial e legitimidade democrática. Atualidades Jurídicas. Revista Eletrônica do Conselho Federal da OAB. 4. ed. $2008 . \quad$ Disponível em: <http://www.oab.org.br/editora/revista/users/revista/1235066670174218181901.pdf> Acesso em: 20 jan. 2014

BICKEL, Alexander. The least dangerous branch: the supreme court at the bar of politics. 2. Ed. New Haven: Yale University Press, 1986.

BRASIL. Constituição da República Federativa do Brasil, de 05 outubro 1988, com emendas.

Disponível

em:

$<$ http://www.planalto.gov.br/ccivil_03/constituicao/constituicaocompilado.htm> Acesso em: 20 mar. 2014

Conselho Nacional de Justiça. Recomendação $\mathbf{n}^{\mathbf{0}}$ 31. Disponível em: $<$ http://www.cnj.jus.br/atos-administrativos/atos-da-presidencia/322-recomendacoes-doconselho/12113-recomendacao-no-31-de-30-de-marco-de-2010> Acesso em: 20 mar. 2014

Conselho Nacional de Justiça. Recomendação $\mathbf{n}^{\mathbf{0}}$ 43. Disponível em: <http://www.cnj.jus.br/atos-administrativos/atos-da-presidencia/322-recomendacoes-doconselho/26014-recomendacao-n-43-de-20-de-agosto-de-2013> Acesso em: 20 mar. 2014 
. Lei $\mathbf{n}^{\mathbf{0}} \mathbf{8 . 0 8 0}$, de 19 setembro 1990. Disponível em: <http://www.planalto.gov.br/ccivil_03/leis/18080.htm> Acesso em: 20 mar. 2014 Lei no 12.401, de 28 abril 2011. Disponível em: http://www.planalto.gov.br/ccivil_03/_Ato2011-2014/2011/Lei/L12401.htm\#art1> Acesso em: 20 mar. 2014

FERRAZ, O., The right to health in the Courts of Brazil: worsening health inequities?. Health Human Rights. n. 11. ed. 2. 2009. p. 33-45.

HOROWITZ, Donald. Judicial Capacity Appraised. In: HOROWITZ, Donald. The Courts and social policy. Massachusetts: The Brookings Institution, 1977. p. 255 299.

MINAS GERAIS, Relatório social. Disponível em: $<$ http://www.social.mg.gov.br/images/stories/galeria_observatorio/relatrio\%20reduzido \%20ids_2012.pdf> Acesso em: 22 outubro 2013.

. Tribunal de Justiça de Minas Gerais. Mapa das comarcas. Disponível em:

$<$ http://www.tjmg.jus.br/portal/conheca-o-tjmg/estrutura-

organizacional/comarcas/detalhe-comarcas-1.htm> Acesso em: 22 outubro 2013.

NUNES, António José Avelãs; SCAFF, Fernando Facury. Os Tribunais e o Direito à Saúde. Porto Alegre: Livraria do Advogado, 2011.

PEIXOTO, I.C.; PEREGRINO, A. A. F., OLIVEIRA, O. V. S.; RAMOS, R. S.. Análise do perfil dos pacientes oncológicos sem possibilidades terapêuticas de cura atuais: verificação da demanda por cuidados paliativos em hospital universitário. Revista Hospital Universitário Pedro Ernesto. v. 10, s.1, 2011. p. 53-63. Disponível em: $<$ http://revista.hupe.uerj.br/detalhe_artigo.asp?id=123> Acesso em: 20 mar. 2014.)

PNUD. Municípios por IDH. Disponível em: $<$ http://www.pnud.org.br/atlas/ranking/Ranking-IDHM-Municipios-2010.aspx > Acesso em: 22 outubro 2013.

POST, Robert; SIEGEL, Reva. Roe Rage: Democratic Constitucionalism and Backlash. Harvard Civil Rights-Civil Liberties Law Review. Public Law Working Paper No. 131. New Heaven: Yale Law School, 2007. ;

ROUSSEAU, Jean Jacques. Do Contrato Social. 3. ed. São Paulo: Martin Claret, 2010. SANTOS, Lenir. (org.) Direito da saúde no Brasil. Campinas: Saberes, 2010.

SARLET, Ingo Wolfgang. A eficácia dos direitos fundamentais. 5. ed. Porto Alegre: Livraria do advogado, 2005.

SOUZA, Jorge Munhós de. Diálogo institucional e direito à saúde. Salvador: JusPodivm, 2013. 